Daniel Pribnow

Masataka Kinoshita

Carol Stein

\title{
Thermal Data Collection
}

and Heat Flow

Recalculations for

\section{Ocean Drilling Program}

Legs 101-180

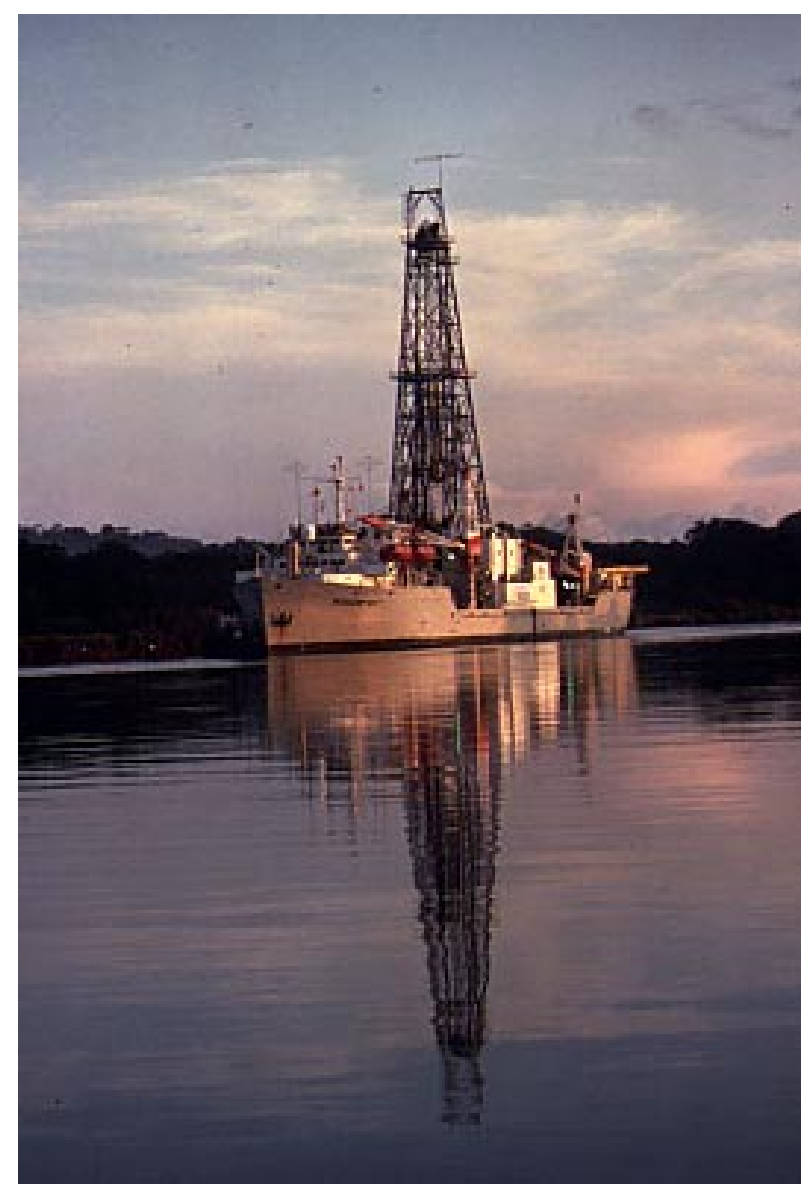




\title{
Institut für
}

\section{Geowissenschaftliche Gemeinschaftsaufgaben (GGA)}

\author{
Thermal Data Collection and \\ Heat Flow Recalculations for \\ Ocean Drilling Program Legs 101-180
}

\author{
Daniel F.C. Pribnow \\ Institute for Joint Geoscientific Research GGA \\ 30655 Hannover, Germany \\ dan.pribnow@gga-hannover.de \\ Masataka Kinoshita \\ School of Marine Science and Technology, Tokai University \\ Shimizu-City, 424-8620, Japan \\ masa@scc.u-tokai.ac.jp \\ Carol A. Stein \\ Dept. of Earth and Environmental Sciences \\ University of Illinois at Chicago \\ Chicago, IL 60607-7059, USA \\ cstein@uic.edu
}

Projekt:

DFG Pr471/2

Datum:

6. Oktober 2000

Archiv Nr.:

0120432 
In memory of Marc G. Langseth

Marc Langseth spent many months at sea making heat flow measurements both at and under the sea floor on ships such as Glomar Challenger and JOIDES Resolution. He organized this project but passed away shortly after this work was initiated.

We will miss him as a colleague and a friend. 
Abstract. In this report the geothermal measurements made with temperature probes on the JOIDES Resolution during legs 101-180 are reanalyzed in a standard systematic manner. Sediment temperatures were measured on 53 of the first 80 Ocean Drilling Project Legs. 205 of the 475 sites have reliable data. For $22 \%$ of sites with reliable values, however, heat flow data were not reported in the Initial Results volumes. A total of 993 reliable temperature measurements yields an average of 4.8 measurements per site. Most temperature measurements were between 20 to $250 \mathrm{mbsf}$, and the deepest depth in this study is $550 \mathrm{mbsf}$. Available thermal conductivity data for these 205 sites were corrected for in-situ conditions. Heat flow values, calculated using the Bullard method, range from $5 \mathrm{~mW} \mathrm{~m}^{-2}$ to $13 \mathrm{~W} \mathrm{~m}^{-2}$. Temperature, thermal conductivity, and heat flow data presented in this report are available from the included CD.

\section{Introduction}

Geothermal measurements are important data needed to study the Earth's processes. The values measured on the JOIDES Resolution during Ocean Drilling Program (ODP) Legs 101180 reflect heat transfer from the interior of the Earth, oceanic lithosphere evolution, continental margin formation, subduction, and hotspot volcanism. In addition, these data are used to examine more shallow processes associated with fluid flow and gas hydrate formation. To calculate heat flow, temperatures with depth and the thermal conductivity of the material in which the temperatures are measured must be known. If the thermal conductivity is constant over the depths over which the temperatures are measured and if heat transfer is essentially vertical and conductive, then heat flow can be calculated using Fourier's Law. In this case,
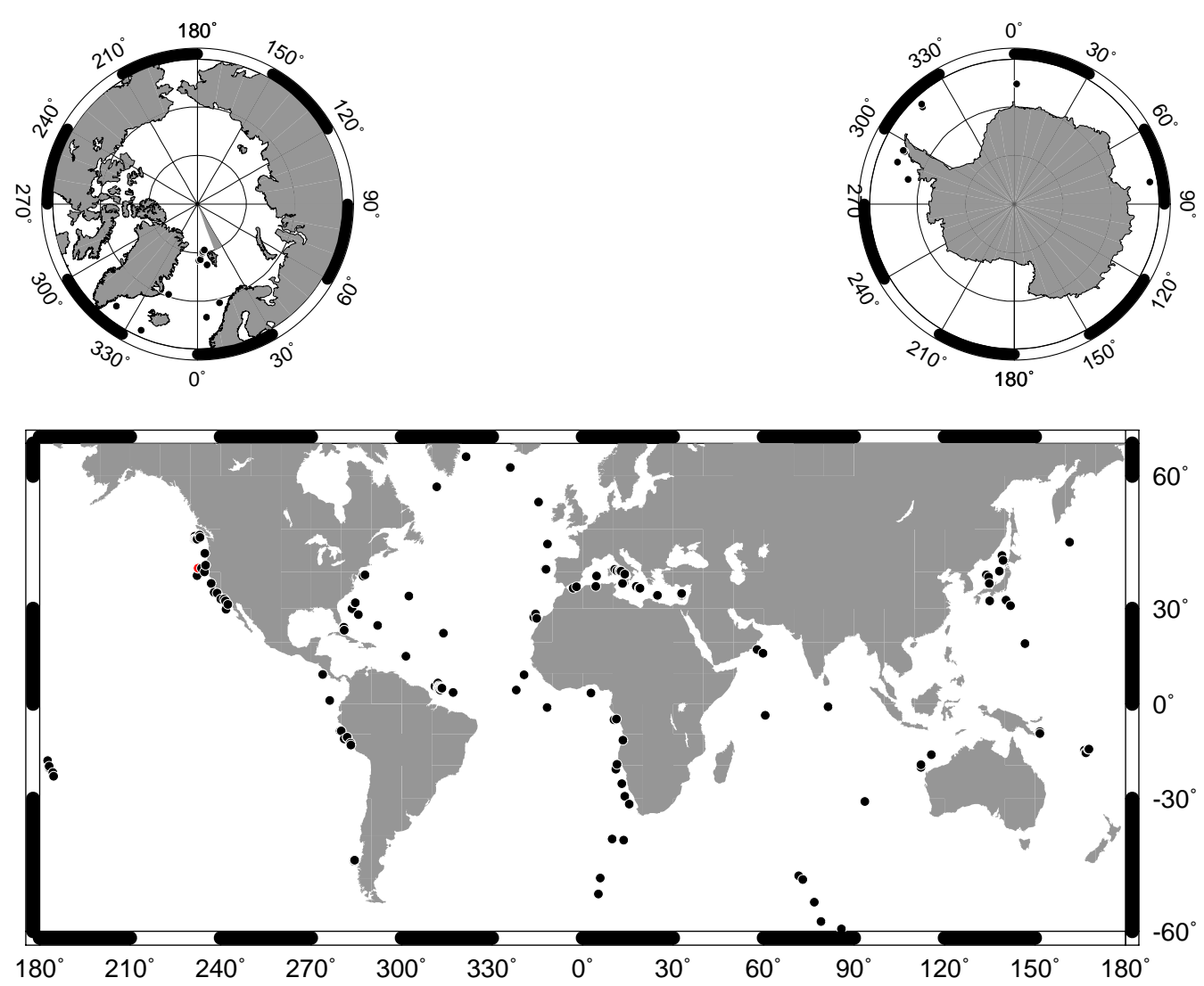

Figure 1: Locations of heat flow measurements from ODP Legs 101-180. 
heat flow is the product of the vertical gradient of the temperature, which is generally positive downwards (temperature increases with depth), and the measured or estimated thermal conductivity of the material. If the thermal conductivity changes with depth, heat flow may be calculated with the Bullard method. In this report, we first review the equipment and methods used to collect and analyze the thermal conductivity and temperature data on the first 80 ODP legs. We then discuss the method used to calculate the heat flow. Next, we report the heat flow for the 205 measurements (Figure 1). Last, we describe how this data can be accessed. We have examined only data from probes inserted into sediments and not from downhole logging. The tectonic implications of these heat flow data will be discussed in a manuscript currently in preparation.

\section{Methods}

\subsection{Thermal Conductivity Shipboard Instrumentation}

Thermal conductivity measurements in the core laboratory on JOIDES Resolution are made using the transient line-source (needle-probe) technique (von Herzen and Maxwell, 1959). The line-source is a cylindrical probe, $2 \mathrm{~mm}$ in diameter and $70 \mathrm{~mm}$ long, that contains a heating wire and a thermistor. The line-source is heated with constant power. Thermal conductivity is calculated from the temperature-time response to the line-source, providing a two-dimensional value for a plane perpendicular to the needle axis. Shipboard measurements are made by pushing the needle-probe horizontally through the core-liner into soft sediments (Figure 2; for details of anisotropy effects, see Pribnow et al., 2000). Two devices are currently available in the core lab.

\section{Thermcon-85}

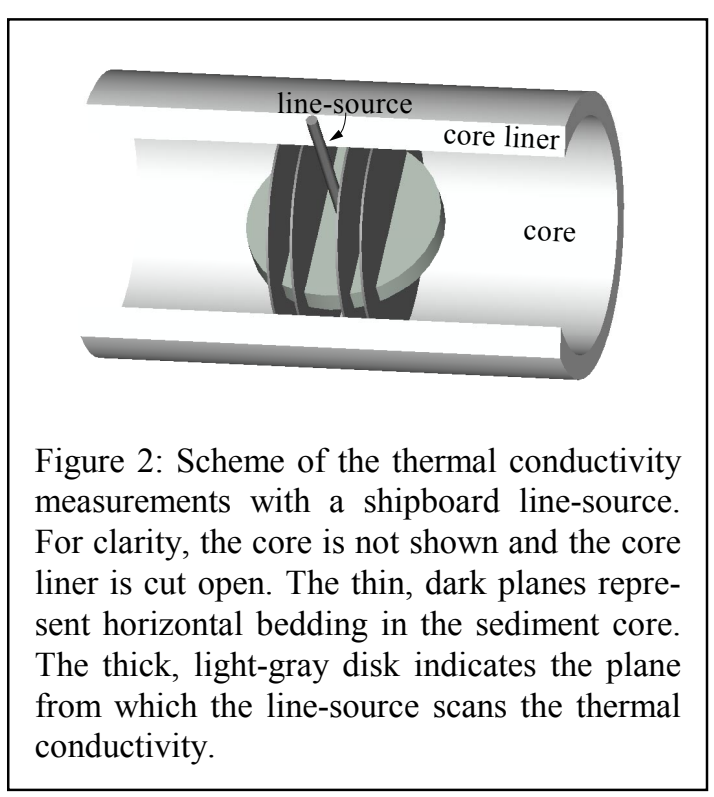

This unit was purchased from Woods Hole Oceanogrphic Institution and the software was developed by ODP in 1991. Up to five needle-probes can be used simultaneously (Davis et al., 1992). The device is calibrated regularly by measuring standards with known conductivity. Precision and accuracy are about 5\%. During the data processing, the operator has to choose manually a time interval from which the thermal conductivity is calculated. The results are dependent on this chosen interval and therefore reproduceability may vary from operator to operator.

\section{TK04}

ODP purchased TK04 in late 1995 and deployed it permanently on the ship during Leg 168 in 1996 (Davis et al., 1997a). A calibration is not required. The main advantage of the TK04 system is a processing algorithm which ensures that only results of physical significance are considered. The critical choice of time interval for calculation of conductivity is accomplished automatically. The algorithm determines the optimal interval. In addition, the solutions can be judged in great detail and the data can be re-processed with different boundary parameters. The precision using extended evaluations is better than $2 \%$. For routine evaluations of repeated measurements, the accuracy is about $5 \%$. 


\subsection{Sediment Temperatures Shipboard Instrumentation}

To infer equilibrium temperatures of the sediments, prior to pertubation by drilling, a sensor is pushed into the sediments just below the bottom of the hole and ahead of the drill bit. One system, the Advanced Piston Corer (APC) tool measures in-situ sediment temperatures during regular piston-coring operations (Davis et al., 1992; Fig. 3). The $A P C$ contains a miniature programmable recorder and battery pack designed to fit inside an annular cavity of a coring shoe. Two steel prongs extend from the base of the frame, one of which contains a platinum resistance-temperature device. The APC also has been referred to as the von Herzen, ADARA (processing software company) or HPC (Hydraulic Piston Corer) temperature tool. The $A P C$ was first used during DSDP Leg 86 (Horai and von Herzen, 1985) and an improved version was introduced during ODP Leg 110 (Davis et al., 1992).

The Water Sampler Temperature Probe (WSTP) is a hybrid of two other tools, the Uyeda Temperature Tool (Yokota et al., 1980) and the Barnes Fluid Sampler (Barnes, 1979). The first generation, also referred to as T Probe or Uyeda Probe, was used until ODP Leg 116. The second generation of WSTP became available during ODP Leg 110 with improved sampling capabilities and a stouter temperature probe (Barnes, 1988). A third version of this tool was introduced during Leg 139 in anticipation of encountering extremely corrosive fluids at high temperatures. The original Uyeda Temperature Tool had a thin, stainless-steel probe which was pushed ahead of the bit into the undisturbed sediments at the bottom hole. The second generation tool had a probe tip with a minimum diameter of $1.3 \mathrm{~cm}$ which extended $8.3 \mathrm{~cm}$ past a $5.1 \mathrm{~cm}$ diameter pore-fluid filter block. The new WSTP includes a temperature tip which is slightly longer (Fig. 4; after Davis et al., 1992). Individual temperature measurements have a nominal resolution of about $0.02 \mathrm{~K}$ (near room temperature); resolution falls off with increasing temperature.

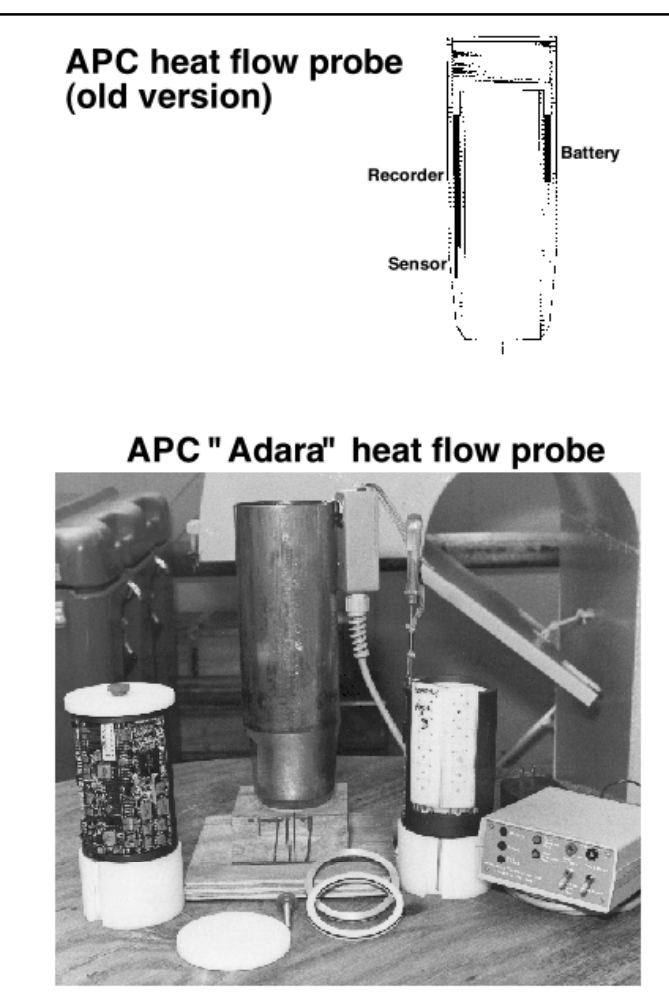

Figure 3: Two generations of the APC temperature tool (Horai and von Herzen, 1985; Davis et al., 1992).

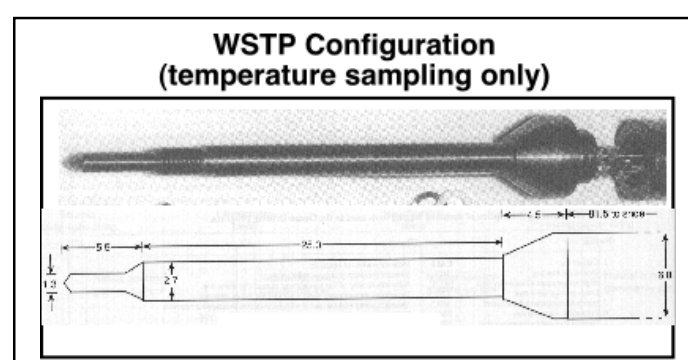

WSTP Configuration (fluid and temperature sampling)

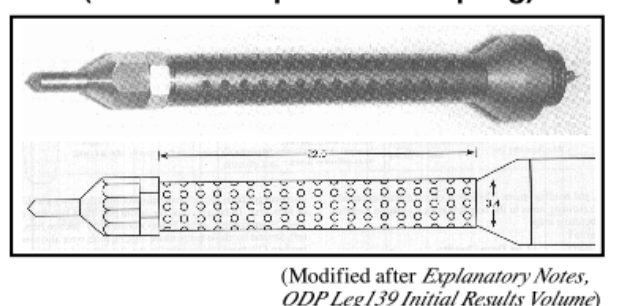

Figure 4: Configuration of the WSTP.

Regardless of which equipment is used to measure temperatures, as the probe is inserted into the sediments it is initially heated due to friction and cools towards the equilibrium temperature. Processing the data to infer the equilibrium temperature involves careful and somewhat subjective fitting of measured temperatures to expected temperature-time curves. The theory behind $A P C$ measurements is described by Horai and von Herzen (1985). The theoreti- 
cal cooling curve after the frictional heating of the $A P C$ is obtained by solving the thermal conduction equation for composite circular cylinders. The temperature of the metal cylinder is modelled as radially isothermal after several tens of seconds because of its high thermal conductivity. The currently used software TFIT was developed by James Craig and Adara Systems Ltd., based on software by Keir Becker (APCFIT).

For the Davis-Villinger Temperature Probe (DVTP; Davis et al., 1997a; 1997b), the theoretical cooling curve is based on an idealized radial heat conduction model that simulates the thermal decay of the instrument following frictional heating from tool insertion. A segment of temperature versus time data from each deployment is compared to a theoretical decay function, and the penentration time of the tool is shifted relative to the model in order to get a best statis-

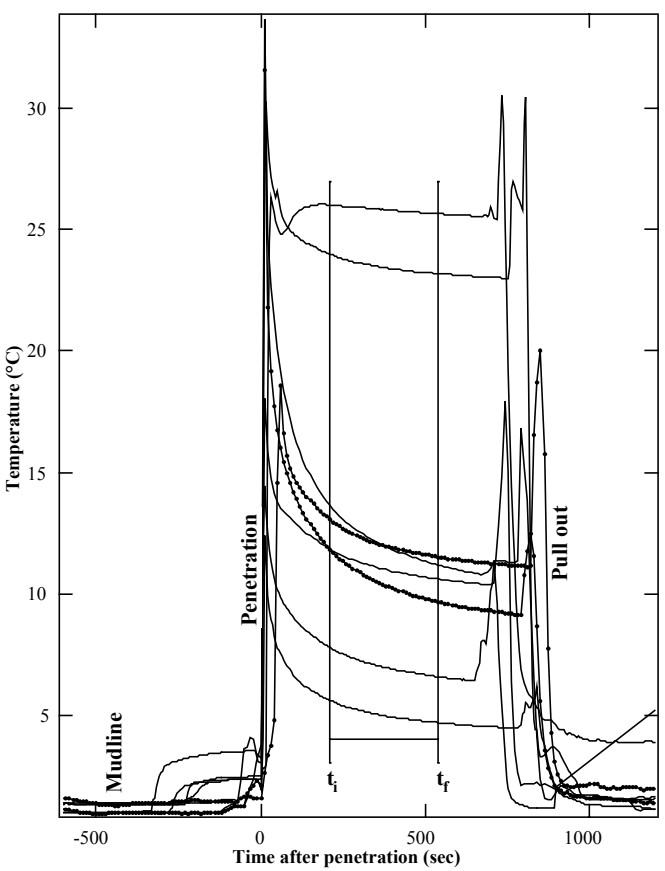

Fig. 5: Example of APC tool measurements. tical (least-squares) fit. The trend of the observations is extrapolated to infinite time.

To estimate undisturbed in-situ temperatures, several versions of reduction software were developed and are supported by ODP. Some of them, including the newest version (TFIT) can interactively determine in-situ temperatures by manually specifying four parameters; penetration time (or the origin time, $t_{\text {or }}$ ), time interval (initial $t_{i}$ and final time $t_{f}$ ) to calculate equilibrium temperatures, and in-situ thermal conductivity. Figure 5 shows a typical example of temperature recorded by the APC tool. The origin time is automatically adjusted to minimize the fitting error (Figure 6). However, $t_{i}$ and $t_{f}$ also significantly affect the results. Selection of these parameters is made arbitrarily by shipboard scientists, although they may keep these values constant during one leg.

To test sensitivities of these parameters to the estimated equilibrium temperatures, fits were done for various sets of time intervals $t_{i}$ and $t_{f}$. Results are presented as contours of both equilibrium temperatures and their standard errors. Figure 7 shows typical examples of high and low quality data. For high quality data, the equilibrium temperatures are almost constant within $0.1^{\circ} \mathrm{C}$ for a moderate range of selected time intervals. On the other hand, the estimated temperatures vary up to $1{ }^{\circ} \mathrm{C}$ with varying time intervals for low quality data. It should be noted that, even for bad quality, temperature vs. time plots appears as good as others. Thus, it is very important to maintain the time intervals constant throughout the analysis.
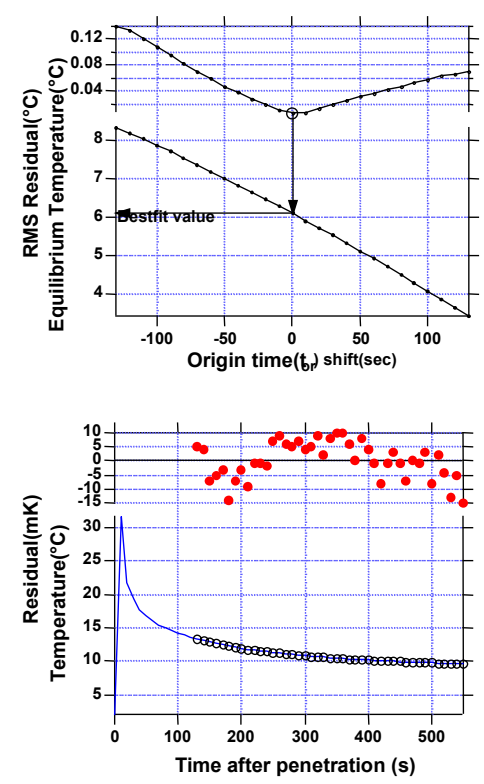

Fig. 6: Results of equilibrium temperature fitting. 
Based on these estimations, we kept the time intervals $t_{i}$ and $t_{f}$ at $210 \mathrm{~s}$ and $540 \mathrm{~s}$ after penetration, respectively. For this interval most estimated temperatures are within the flat region in the contour diagram (Figure 7). However, for a few cases where the frictional decay is extremely large, we changed these values because they produced unrealistic equilibrium temperatures. Instead, we used a longer interval. The new results match within a few tenth ${ }^{\circ} \mathrm{C}$, although in some cases both results differ by up to $0.5^{\circ} \mathrm{C}$ or more.

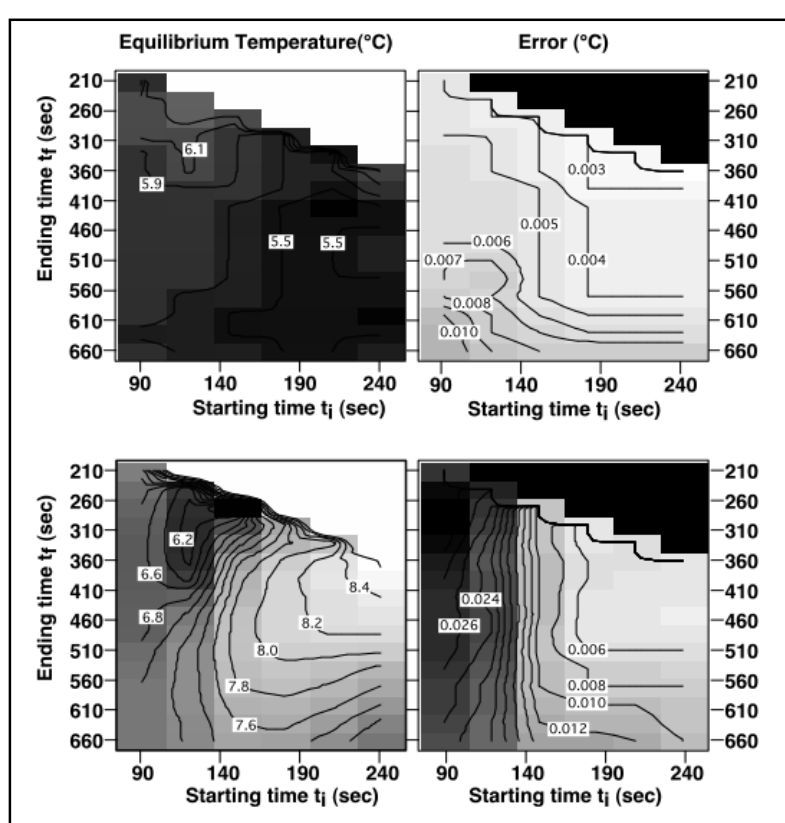

Fig. 7: Typical examples of high (top) and low (bottom) quality records. 


\subsection{Heat Flow Calculation}

\subsubsection{The Bullard Method}

The Bullard (1939) method was introduced to calculate heat flow from borehole data when there is significant variation of thermal conductivity within the depth range over which the temperatures have been measured. It assumes a linear relation between temperature $T$ and thermal resistance $\Omega$ of the sediments:

$$
T(z)=T_{0}+q \cdot \Omega(z)
$$

where $z$ is depth, $T_{0}$ is the surface temperature $(z=0), q$ is heat flow, and the thermal resistance is:

$$
\Omega(z)=\int_{0}^{z} \frac{d z}{\lambda(z)} \approx \sum_{i=1}^{I} \frac{z_{i}-z_{i-1}}{\lambda_{i}}
$$

with $z_{\mathrm{i}}$ and $z_{\mathrm{i}-1}$ as bottom and top depths, respectively, of a horizontal layer with thermal conductivity $\lambda_{\mathrm{i}} . I$ is the number of layers between the surface and depth $z$. If $\Omega(z)$ is plotted versus $T(z)$ in the so-called Bullard plot, a linear regression allows estimation of the surface temperature $\left(T_{0}\right)$ from the intercept with $z=0$ and of heat flow $(q)$ from the slope (eq. 1). A Bullard plot will be linear if conditions are conductive, steady state, and there are no internal heat sources.

\subsubsection{Thermal Resistance}

To calculate heat flow with the Bullard method (eq. 1), the thermal resistance $\Omega$ is required at the depths of available temperature values $z_{\mathrm{T}, \mathrm{j}}$ which are typically not coincident with the depths of measured thermal conductivity values $z_{\lambda, \mathrm{k}}$. By transforming thermal conductivity values from discrete depths $\left(\lambda_{\mathrm{k}}\right)$ into continuous profiles $\lambda(z)$, thermal resistance $\left(\Omega_{\mathrm{j}}\right)$ can be calculated for the depths of temperature measurements $\left(T_{\mathrm{j}}\right)$. In this study, three different approaches for continuous conductivity profiles are used, based on the characteristics of the individual sites: (1) the average approach, where no systematic trend of thermal conductivity with depth is observed; (2) the linear approach, assuming a systematic and linear variation of thermal conductivity with depth; and (3) the porosity approach, based on the assumtion of exponentially decreasing porosity with depth and the geometric mean model as a mixing law for sediment-matrix and pore-water thermal conductivity.

2.3.2.1 The average approach is based on the assumption that there is no systematic variation of thermal conductivity with depth. It is also appropriate for situations where the number of measurements is insufficient to characterize possible systematic variations properly. The continuous profile is a constant value, $\lambda_{\mathrm{AVG}}$, calculated from all thermal conductivity measurements, $\lambda_{k}$ :

$$
\lambda_{A V G}=\frac{1}{K} \cdot \sum_{k=1}^{K} \lambda_{k}
$$

Based on this approach and solving the integral in equation (2), the thermal resistance, $\Omega_{\mathrm{AVG}}$, for the depth, $z_{\mathrm{T}, \mathrm{j}}$, of the $j^{\text {th }}$ temperature value, $T_{\mathrm{j}}$, is calculated with:

$$
\Omega_{A V G, j}=\frac{z_{T, j}}{\lambda_{A V G}}
$$


2.3.2.2 The linear approach is based on the assumption that there is a systematic and linear variation of thermal conductivity with depth. For example, a reduction of porosity with depth due to compaction results in a systematic increase of conductivity with depth. Alternatively, increasing temperature with depth results in a systematic conductivity decrease with depth. The continuous profile is represented by a straight line,

$$
\lambda_{\text {LIN }}(z)=\lambda_{0}+\Gamma \cdot z
$$

calculated from a linear regression of all thermal conductivity measurements, $\left[\lambda_{\mathrm{k}}, z_{\lambda, \mathrm{k}}\right]$. Based on this approach and solving the integral in equation (2), the thermal resistance, $\Omega_{\mathrm{LIN}}$, for the depth, $z_{\mathrm{T}, \mathrm{j}}$, of the $j^{\text {th }}$ temperature value, $T_{\mathrm{j}}$, is calculated using the results of the linear regression, $\lambda_{0}$ (calculated surface thermal conductivity) and $\Gamma$ (slope), with:

$$
\Omega_{L I N, j}=\frac{\ln \left(\lambda_{0}+\Gamma \cdot z_{T, j}\right)-\ln \left(\lambda_{0}\right)}{\Gamma}
$$

2.3.2.3 The porosity-related approach is based on two assumptions resulting in a systematic and non-linear increase of thermal conductivity. It is especially appropriate for seafloor sediments where porosity can change rapidly in the upper section.

1) Due to compaction, porosity $\phi$ decreases exponentially with depth;

$$
\phi(z)=\phi_{0} \cdot \exp \left\{\frac{z}{-D}\right\}
$$

where $\phi_{0}$ is the porosity at $z=0$ and $D$ is the characteristic depth.

2) The bulk thermal conductivity, $\lambda_{\mathrm{COM}}(z)$, is the geometric mean of the fluid conductivity, $\lambda_{\mathrm{f}}$, and the matrix conductivity, $\lambda_{\mathrm{m}}$, weighted with the porosity, $\phi(z)$, and the matrix volume, $(1-\phi(z))$, respectively;

$$
\lambda_{\text {COM }}(z)=\left(\lambda_{f}\right)^{\phi(z)} \cdot\left(\lambda_{m}\right)^{1-\phi(z)}
$$

Based on these assumptions, the thermal resistance, $\Omega_{\mathrm{COM}}$, for the depth, $z_{\mathrm{T}, \mathrm{j}}$, of the $j^{\text {th }}$ temperature value, $T_{\mathrm{j}}$, is calculated using the thermal conductivity of water $\lambda_{\mathrm{f}}=0.6 \mathrm{~W} \mathrm{~m}^{-1} \mathrm{~K}^{-1}$, and $\lambda_{\mathrm{m}}, \phi_{0}, D$ from a least square fit of all thermal conductivity measurements $\left[\lambda_{\mathrm{k}}, z_{\lambda, \mathrm{k}}\right]$ with $k=1$, $K$. The integral in equation (2) becomes

with $A=\left(\frac{\lambda_{f}}{\lambda_{m}}\right)^{-\phi_{0}}: \quad \Omega_{C O M, j}=\frac{1}{\lambda_{m}} \int_{0}^{z_{T, j}}(A)^{\exp \left\{\frac{z}{-D}\right\}} d z$

The solution of this integral leads to the exponential intergral function $E i$

$$
\Omega_{\text {СOM }, j}=\frac{-D \cdot A}{\lambda_{m}} \cdot\left(\operatorname{Ei}(\ln (A))-E i\left(\ln (A) \cdot \exp \left\{\frac{z_{T, J}}{-D}\right\}\right)\right)
$$

with: $\operatorname{Ei}(a x)=\int \frac{\exp \{a x\}}{x} d x$. 


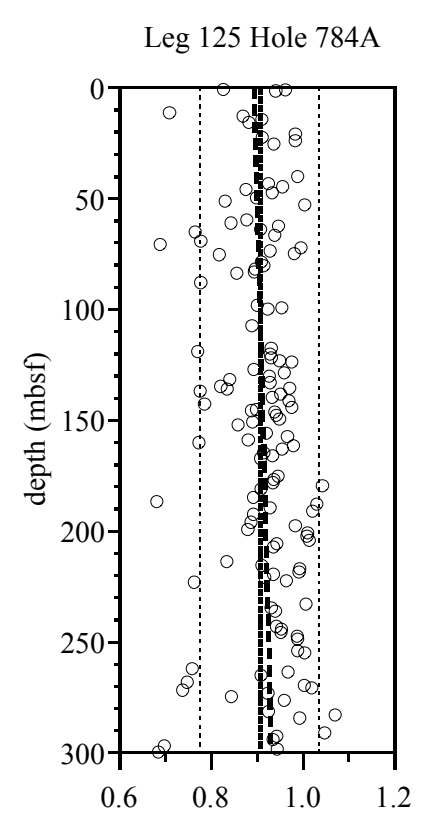

thermal conductivity $\left(\mathrm{W} \mathrm{m}^{-1} \mathrm{~K}^{-1}\right)$
Leg 122 Hole $763 \mathrm{~A}$

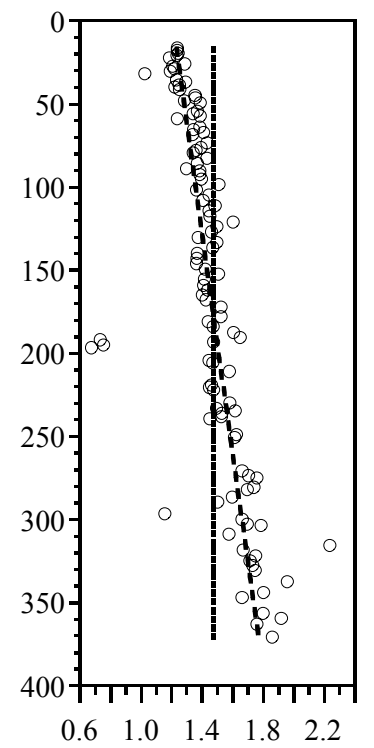

thermal conductivity $\left(\mathrm{W} \mathrm{m}^{-1} \mathrm{~K}^{-1}\right)$
Leg 120 Hole 747A

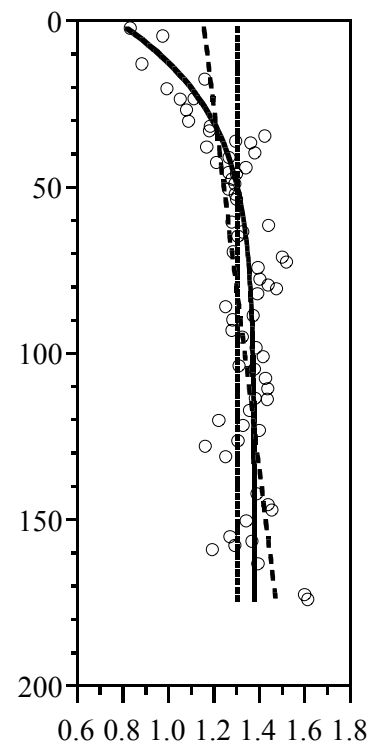

thermal conductivity $\left(\mathrm{W} \mathrm{m}^{-1} \mathrm{~K}^{-1}\right)$

Figure 8: Examples for continuous thermal conducitivity approaches. Individual laboratory measurements have been corrected for in-situ conditions (see text). Dotted lines: average approach (eq. 3), dashed lines: linear approach (eq. 5); solid line: porosity approach (eq. 8);

Left: Hole 784A, average: $0.91 \mathrm{~W} \mathrm{~m}^{-1} \mathrm{~K}^{-1}$, standard deviation of average (sdev): $\pm 0.13 \mathrm{~W} \mathrm{~m}^{-1} \mathrm{~K}^{-1}$, intercept of linear regression $\left(\lambda_{0}\right): 0.89 \mathrm{~W} \mathrm{~m}^{-1} \mathrm{~K}^{-1}$, slope of linear regression $(\Gamma): 0.13 \mathrm{~W} \mathrm{~m}^{-1} \mathrm{~K}^{-1} \mathrm{~km}^{-1}$;

Center: Hole $763 \mathrm{~A}$, average: $1.46 \mathrm{~W} \mathrm{~m}^{-1} \mathrm{~K}^{-1}$, sdev: $\pm 0.23 \mathrm{~W} \mathrm{~m}^{-1} \mathrm{~K}^{-1}, \lambda_{0}: 1.21 \mathrm{~W} \mathrm{~m}^{-1} \mathrm{~K}^{-1}, \Gamma: 1.52$ $\mathrm{W} \mathrm{m} \mathrm{K}^{-1} \mathrm{~K}^{-1} \mathrm{~km}$;

Right: Hole 747A, average: $1.30 \mathrm{~W} \mathrm{~m}^{-1} \mathrm{~K}^{-1}$, sdev: $\pm 0.15 \mathrm{~W} \mathrm{~m}^{-1} \mathrm{~K}^{-1}, \lambda_{0}: 1.15 \mathrm{~W} \mathrm{~m}^{-1} \mathrm{~K}^{-1}, \Gamma: 1.84$ $\mathrm{W} \mathrm{m} \mathrm{K}^{-1} \mathrm{~km}^{-1}$, porosity approach: $1.38 \mathrm{~W} \mathrm{~m}^{-1} \mathrm{~K}^{-1}$ matrix conductivity, $70 \%$ porosity at sea floor and $21.5 \mathrm{~m}$ characteristic depth.

A reasonable approximation of $\Omega_{\mathrm{COM}}$ can also be obtained by using the least square fit directly to calculate the thermal resistance. $\lambda_{\mathrm{COM}}\left(z_{\mathrm{i}}\right)$ is calculated using equations (7) and (8) with the results of the least square fit, $\lambda_{\mathrm{m}}, \phi_{0}, D$, and $\lambda_{\mathrm{f}}=0.6 \mathrm{~W} \mathrm{~m}^{-1} \mathrm{~K}^{-1}$ for regular depth intervals between the surface, $z=0$, and the depth, $z_{\mathrm{T}, \mathrm{J}}$, of the last temperature measurement, $T_{\mathrm{j}}$,

$$
0 \leq z_{i}=i \cdot \frac{z_{T, J}}{I} \leq z_{T, J}, i=1, I
$$

The thermal resistance, $\Omega_{\mathrm{COM}}$, for the depth, $z_{\mathrm{T}, \mathrm{j}}$, of the $j^{\text {th }}$ temperature value, $T_{\mathrm{j}}$, is then calculated based on the discrete step function approach

$$
\text { for all } i \text { with } z_{i} \leq z_{T, j} \quad \Omega_{\mathrm{COM}, \mathrm{j}}=\sum_{\mathrm{i}=1}^{\mathrm{N}} \frac{\mathrm{z}_{\mathrm{i}}}{\lambda_{\mathrm{COM}}\left(\mathrm{z}_{\mathrm{i}}\right)}
$$

The number of used depth intervals, $I$, controls the accuracy of this approximation.

The choice of the appropriate method to obtain a continuous conductivity profile depends on the characteristics of the individual conductivity measurements with depth. Figure 8 shows examples for the three continuous thermal conductivity approaches. In the first case (Hole 784A), the average approach is most appropriate. The amount and scatter of the individual conductivity data do not indicate any systematic variation with depth. The trend of a 
linear fit is well within the standard deviation of the average (sdev). Thus, the continuous approach for this case is $\lambda(z)=0.91 \mathrm{~W} \mathrm{~m}^{-1} \mathrm{~K}^{-1}$.

The second example in Figure 8 (Hole 763A) shows a clear linear trend of conductivity with depth. The average approach is not appropriate, as indicated by the large sdev. In this case, the continuous approach is $\lambda(z)=1.21+1.52 \cdot 10^{-3} \cdot z \mathrm{~W} \mathrm{~m}^{-1} \mathrm{~K}^{-1}$.

For the third example (Hole 747A), the porosity approach is most appropriate to represent a continuous thermal conductivity profile, especially in the upper $40 \mathrm{mbsf}$. The least squares fit of the data yields reasonable values: $1.38 \mathrm{~W} \mathrm{~m}^{-1} \mathrm{~K}^{-1}$ matrix conductivity, $70 \%$ porosity at the sea floor and $21.5 \mathrm{~m}$ as the characteristic depth $(D)$ for an exponential decrease of porosity. Neither the average nor the linear approach represent the individual conductivity data appropriately. Here, the continuous approach is $\lambda(z)=0.61^{\phi(z)} \cdot 1.38^{\phi(z)} \mathrm{W} \mathrm{m}^{-1} \mathrm{~K}^{-1}$, with porosity $\phi(z)=0.70 \cdot \exp \{-z / 21.5\}$. For the case of step-wise variations due to lithological changes, the approaches are performed for each section separately.

\subsubsection{Thermal Conductivity Corrections}

Thermal conductivity is dependent on temperature and pressure (e.g., Clark, 1966; Clauser and Huenges, 1995). Laboratory measurements thus need to be corrected for appropriate in-situ conditions. In this study, we use the correction of Hyndman et al. (1974):

$$
\lambda_{P, T}(z)=\lambda_{l a b} \cdot\left(1+\frac{z_{w}+\rho \cdot z}{1829 \cdot 100}+\frac{T(z)-T_{l a b}}{4 \cdot 100}\right)
$$

where $\lambda_{\mathrm{P}, \mathrm{T}}(\mathrm{z})$ is the in-situ thermal conductivity at depth $z$ (mbsf), $\lambda_{\text {lab }}$ is the value measured in the laboratory, $z_{\mathrm{w}}$ is water depth, $\rho$ is mean sediment density $\left(\mathrm{g} \mathrm{cm}^{-3}\right), T(z)$ is the in-situ temperature, and $T_{\text {lab }}$ is sample temperature during the thermal conductivity measurement. This correction considers pressure (center term) and temperature (right term) effects based on studies by Ratcliffe (1960). The valid temperature range is 5 to $25^{\circ} \mathrm{C}$, which is appropriate for most but not all applications in this study. Sediment density was set to $1.8 \mathrm{~g} \mathrm{~cm}^{-3}$ for all calculations. For sites with temperatures exceeding $25^{\circ} \mathrm{C}$, the correction was still applied for reasons of consistency and the lack of alternatives. These sites with questionable in-situ corrections are marked in the final heat flow table. 


\subsubsection{Heat Production}

Radiogenic heat production is caused by transforming kinetic energy of particles, which are emitted during the decay of uranium, potassium and thorium, into heat. The produced heat contributes cummulatively to heat flow through the crust. Nearer to the surface, the total thickness of the heat producing layer increases and hence there is an increase in the total heat flow with depths nearer to the surface, and thus, a non-linear Bullard plot.

To assess the significance of marine sediment heat production for heat flow through oceanic crust, we used gamma-ray spectra from Hole 948C (Leg 156) measured in the borehole (Leg 156 IR volume) and from cores (Blum et al., 1997) to calculate the heat production rate (Rybach, 1976). Figure 9 shows that the reduction of heat flow within $600 \mathrm{~m}$ is less than $0.5 \%$ of the sea floor value. Hence, effects of the radiogenic heat production in marine sediments are not included in this study.

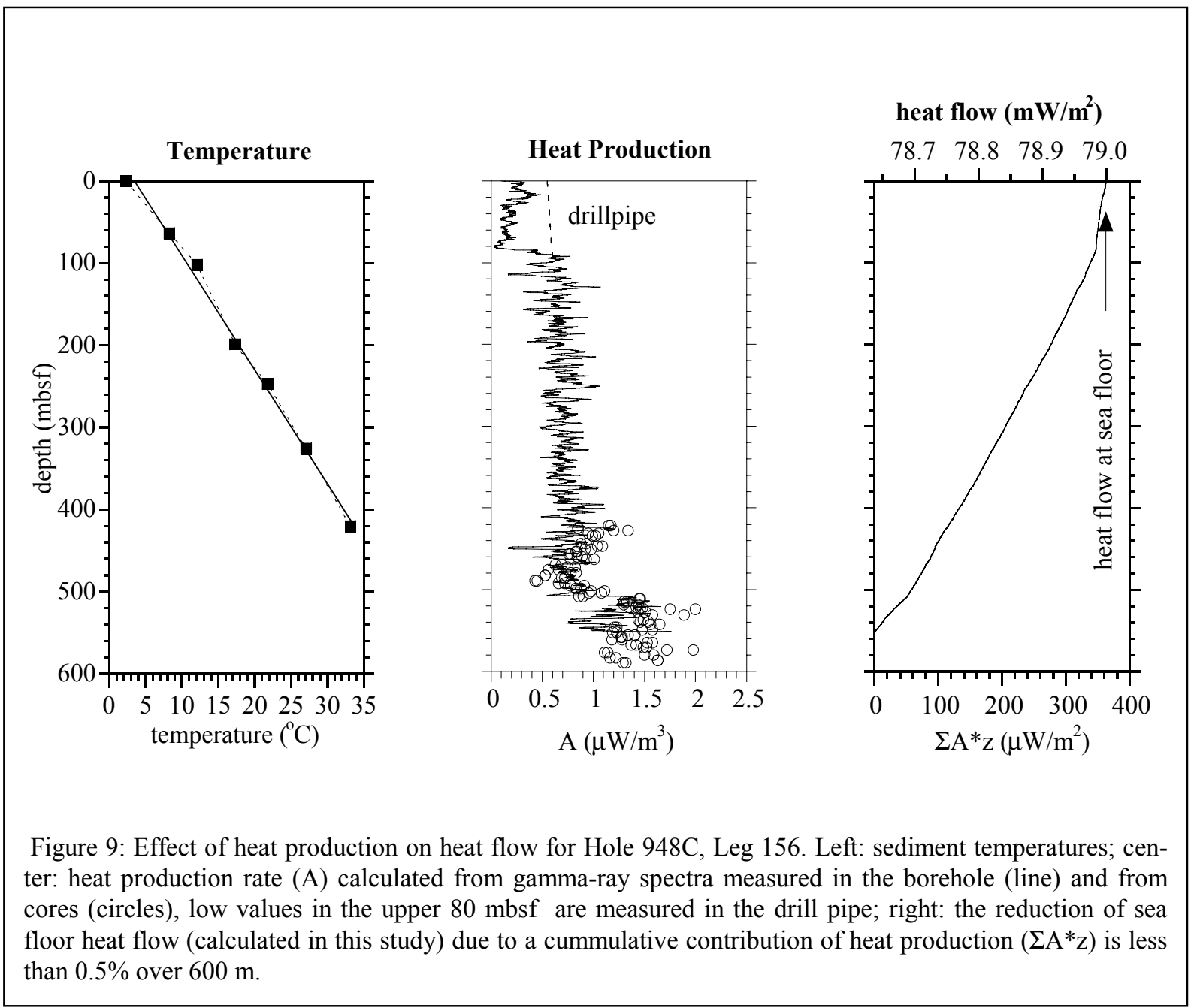




\subsubsection{Heat Flow}

To calculate heat flow, the final step is a linear regression of the thermal resistance vs. temperature data (eq. 1). A typical example from this study is shown in Figure 10 for Hole 747A (Leg 120). Using the appropriate approach for the continuous thermal conductivity profile (Section 2.3.2; Figure 8) and the resulting thermal resistance, improves the linearity of the Bullard Plot. This means that the decrease of temperature gradient with depth can be related to a thermal conductivity increase if the best fit for individual measurements is used. The final result is derived from the linear regression of all data $\left(49 \mathrm{~mW} \mathrm{~m}^{-2}\right)$.
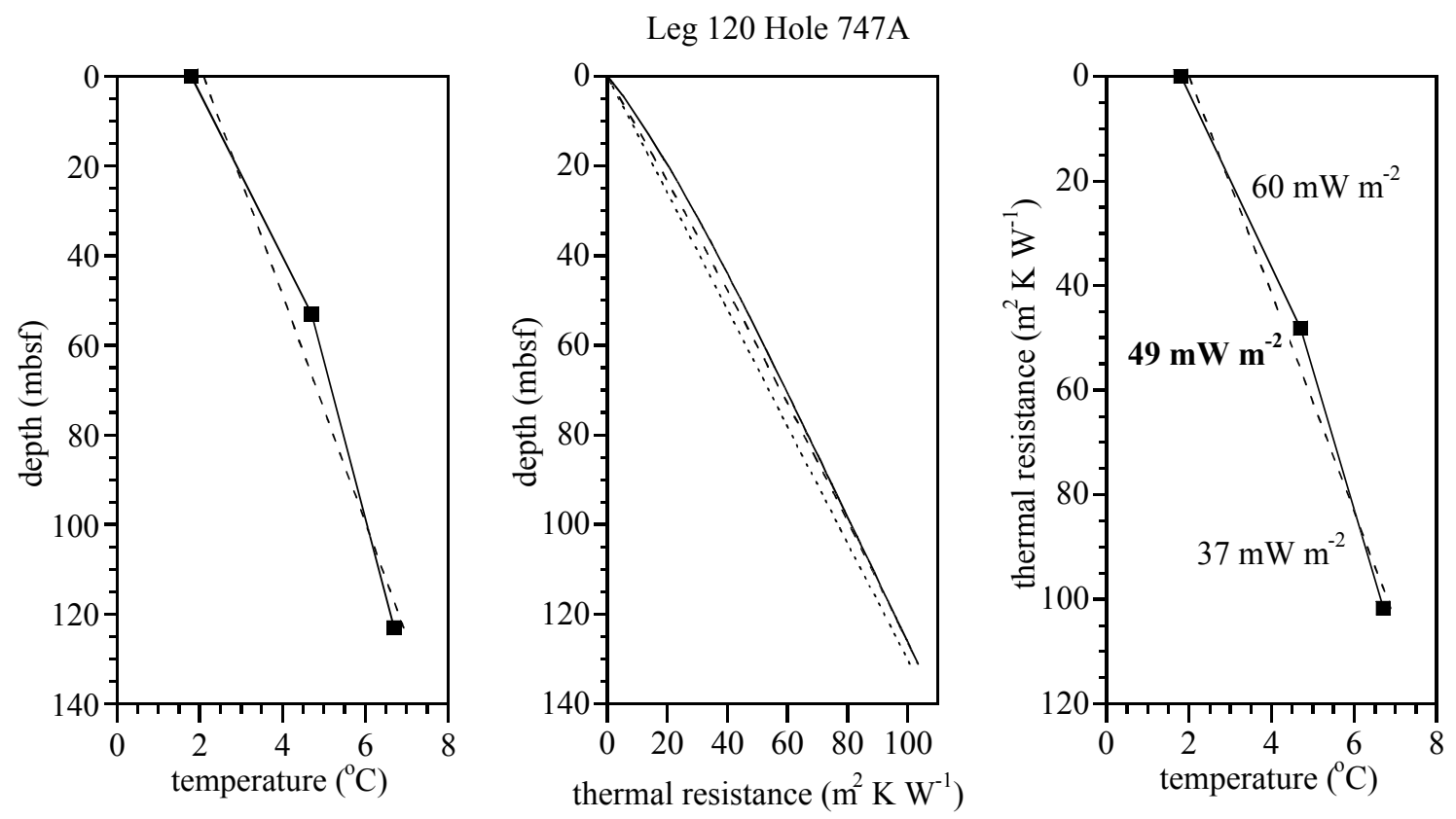

Figure 10: Example of heat flow calculation for Hole 747A, Leg 120. Left: sediment temperatures; center: thermal resistance based on continuous thermal conductivity approach (Fig. 8), dotted line: average, dashed line: linear, solid line: porosity related; right: Bullard Plot, heat flow is calculated individually for each temperature value $\left(60\right.$ and $\left.37 \mathrm{~mW} \mathrm{~m}^{-2}\right)$ and from a linear regression of all data (dashed line; $49 \mathrm{~mW} \mathrm{~m}^{-2}$ ). 


\section{Thermal Data from Legs 101 - 180}

Thermal data for Legs 101 - 180 were compiled from ODP Initial Results (IR) Volumes and the ODP data base at Texas A\&M University (TAMU) in College Station, Texas. These data include shipboard measurements of thermal conductivity and borehole measurements of sediment temperatures.

\subsection{Sediment Temperatures}

From the first 80 ODP Legs with 475 sites, reliable sediment temperatures were measured at 205 sites from 53 Legs. For Legs 111, 121, 128 and 135, sediment temperatures are available in figures only and had to be scanned. Only raw data were available for Legs 174, 175, 177 , and 178 . The original temperature-time data of the measurements are available at TAMU and were used to recalculate the equilibrium value in a consistent manner for a total of 55 sites (see

Section 2.2). A total of 993 individual temperature values yields an average of 4.8 measurements per site (Figure 11). The maximum depth of available measurements is $550 \mathrm{mbsf}$. Temperatures range from $-0.9{ }^{\circ} \mathrm{C}$ to $208{ }^{\circ} \mathrm{C}$, and the average gradient is 179 $\mathrm{K} \mathrm{km}^{-1}$. Sea floor temperatures are measured in the drill string by monitoring for several minutes at the corresponding depth below rig floor. These values are of special interest because they define the temperature gradient in the uppermost part of the sea floor. For about $30 \%$ of the sites, however, this attempt was not made (or not reported) and sea floor temperatures had to be determined by extrapolation of sediment temperatures. Of the total 993 temperature values, 145 are from the seafloor, varying from $-0.9^{\circ} \mathrm{C}$ to $+18.7^{\circ} \mathrm{C}$ with an average of $4.2^{\circ} \mathrm{C}$. Figure 12 shows all sediment temperatures used in this study.

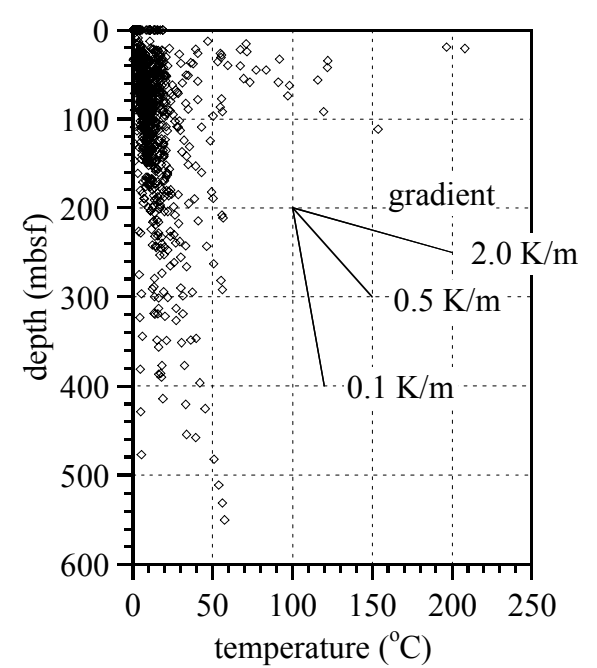

Figure 12: Sediment temperatures from Legs 101- 180 used for this study together with example temperature gradients. 


\subsection{Shipboard Thermal Conductivity}

We used ODP thermal conductivity data only for sites with available and reliable sediment temperatures. For 15 sites (Legs 109, 111, 155), no measurements are reported and sediment conductivity was estimated. About $2 \%$ of the available data were lower than the thermal conductivity of sea water $\left(0.6 \mathrm{~W} \mathrm{~m}^{-1} \mathrm{~K}^{-1}\right)$ and therefore neglected. A total of 15477 thermal conductivity measurements with a maximum depth of 1070 mbsf are used in this study (Fig. 13). The data from 205 sites were fitted with the average approach (eq. 3) for 72 sites (35\%), with the linear approach (eq. 5) for 88 sites $(43 \%)$, and with the porosity approach (eq. 8 ) for 45 sites $(22 \%)$.

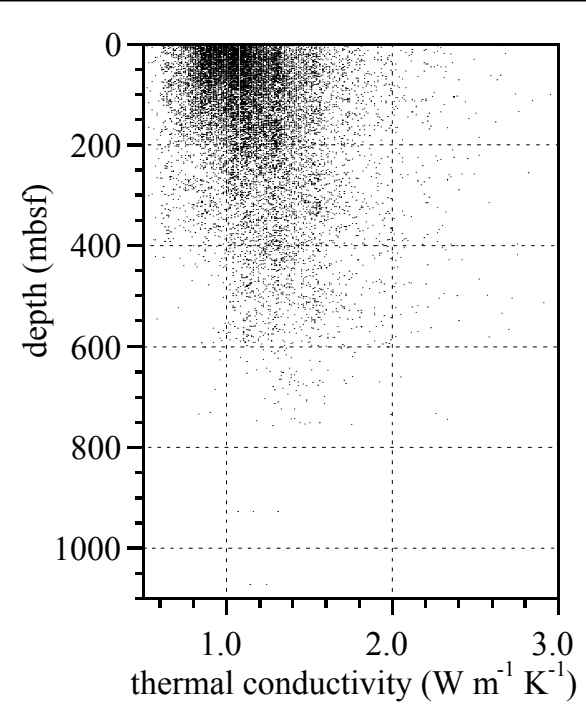

Figure 13: Sediment thermal conductivity from shipboard measurements of Legs 101180. 


\section{Recalculated Heat Flow}

Heat flow values were reported in the IR volumes for 160 sites from Legs 101-180 (i.e. only $78 \%$ of the sites with available and reliable temperature measurements). We recalculated heat flow for all 205 sites in a consistent manner (see Section 2.3). Differences to the reported values are related to (1) the chosen method to calculate heat flow, (2) consideration of all available temperature values in this study (no elimination of socalled "obvious outliers"), and (3) the in-situ correction for laboratory thermal conductivity measurements. The intention of this study is to provide comparable results by applying identical procedures to all sites. In special cases, e.g. with fluid flow in the sediments or very high heat flow, this strategy can result in large differences to the reported values, where specific conditions were considered by the individual scientists. In these cases, our data collection provides the opportunity for other researchers to perform their own calculations and corrections. Figure 14 shows a histogram of the relative differences between reported and recalculated heat flow values.

Recalculated heat flow

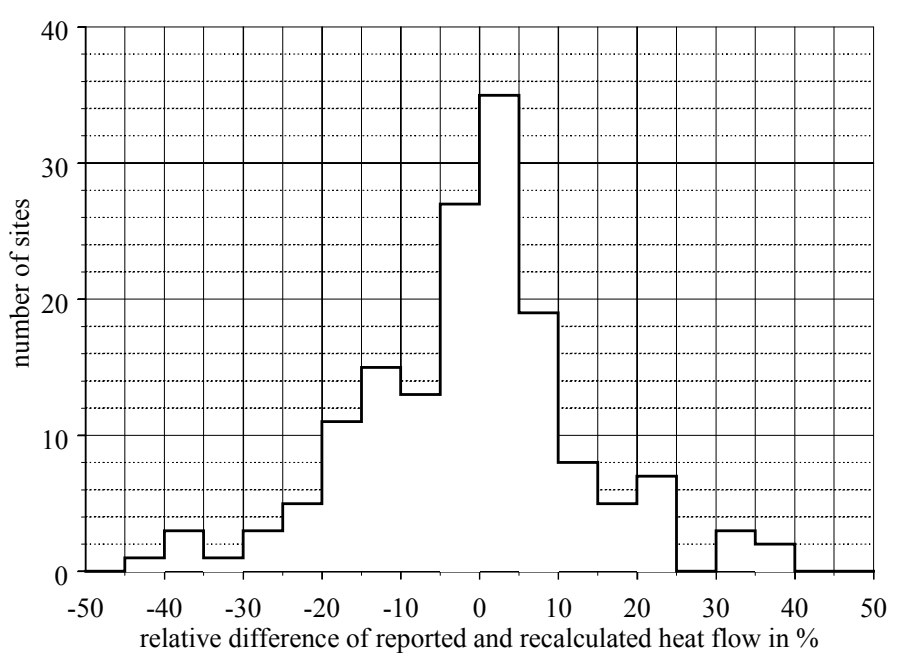

Figure 14: Histogram of relative differences between reported and recalculated heat flow values. A positive value indicates that the recalculated value is larger than the reported.

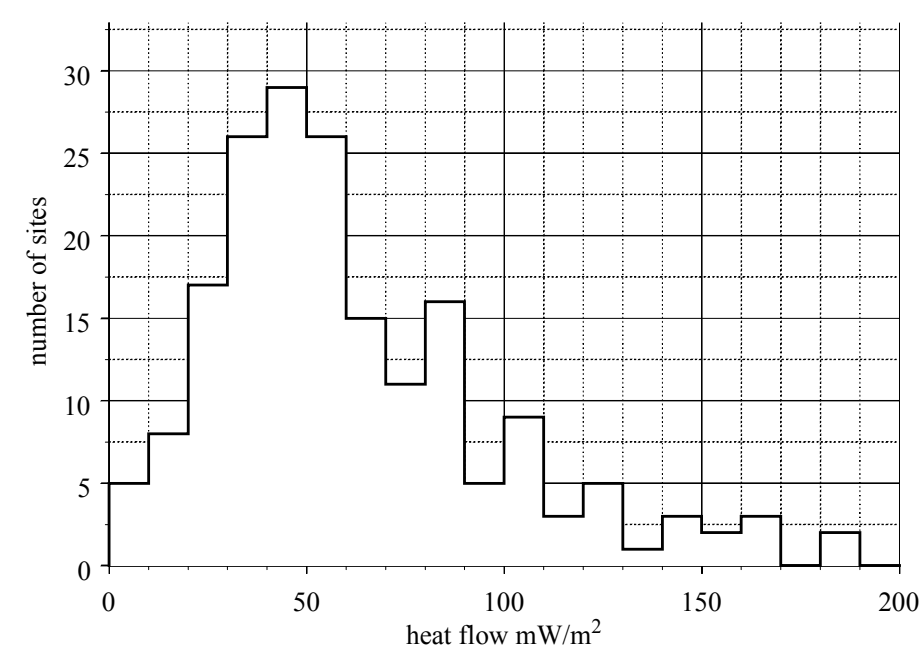

Figure 15: Histogram of recalculated heat flow values less than $200 \mathrm{~mW} / \mathrm{m}^{2}(90 \%$ of the data $)$.

values range from $5 \mathrm{~mW} / \mathrm{m}^{2}$ to $13 \mathrm{~W} \mathrm{~m}^{-2}$. Figure 15 shows a histogram of the heat flow values less than $200 \mathrm{~mW} \mathrm{~m}^{-2}\left(90 \%\right.$ of the data) with the most common values between $30 \mathrm{~mW} \mathrm{~m}^{-2}$ and $60 \mathrm{~mW} \mathrm{~m}^{-2}$. 
Our heat flow values for the 205 ODP sites and the values from shallow sea floor measurements (Davis et al., 1997c) are shown in Figure 16. The quality of the recalculated heat flow values is evaluated by the following method:

A Uncertainty of recalculated heat flow less than $10 \%$

at least two sediment temperature values and

a linear temperature gradient and

sufficient number of thermal conductivity values

B Uncertainty of recalculated heat flow between $10 \%$ and $20 \%$

minor deviations from linear temperature gradient or

insufficient number of thermal conductivity values

C Uncertainty of recalculated heat flow larger than $20 \%$

only one sediment temperature value or

temperatures scanned from figures or

major deviations from linear temperature gradient or

no thermal conductivity values available or

in-situ correction for thermal conductivity questionable

Of the total 205 heat flow sites, 93 were rated A, 55 were rated B, and 57 were rated C.

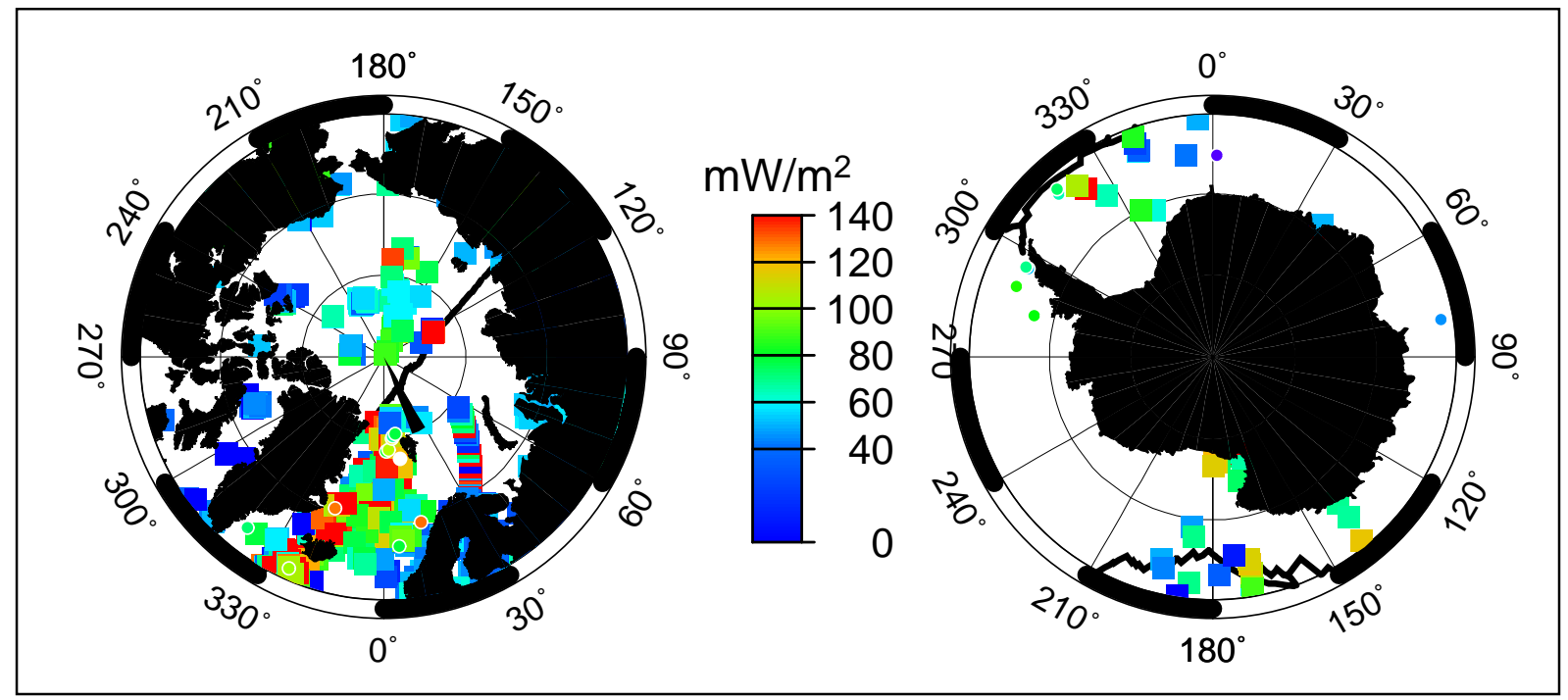

Figure 16: ODP sites with recalculated heat flow (white circles) in comparison with shallow sea floor measurements contoured on a $5^{\circ} \times 5^{\circ}$ grid. This page: North- and South Pole areas; next page: global view. White areas indicate no measurements in a grid. Solid black lines are plate boundaries. 


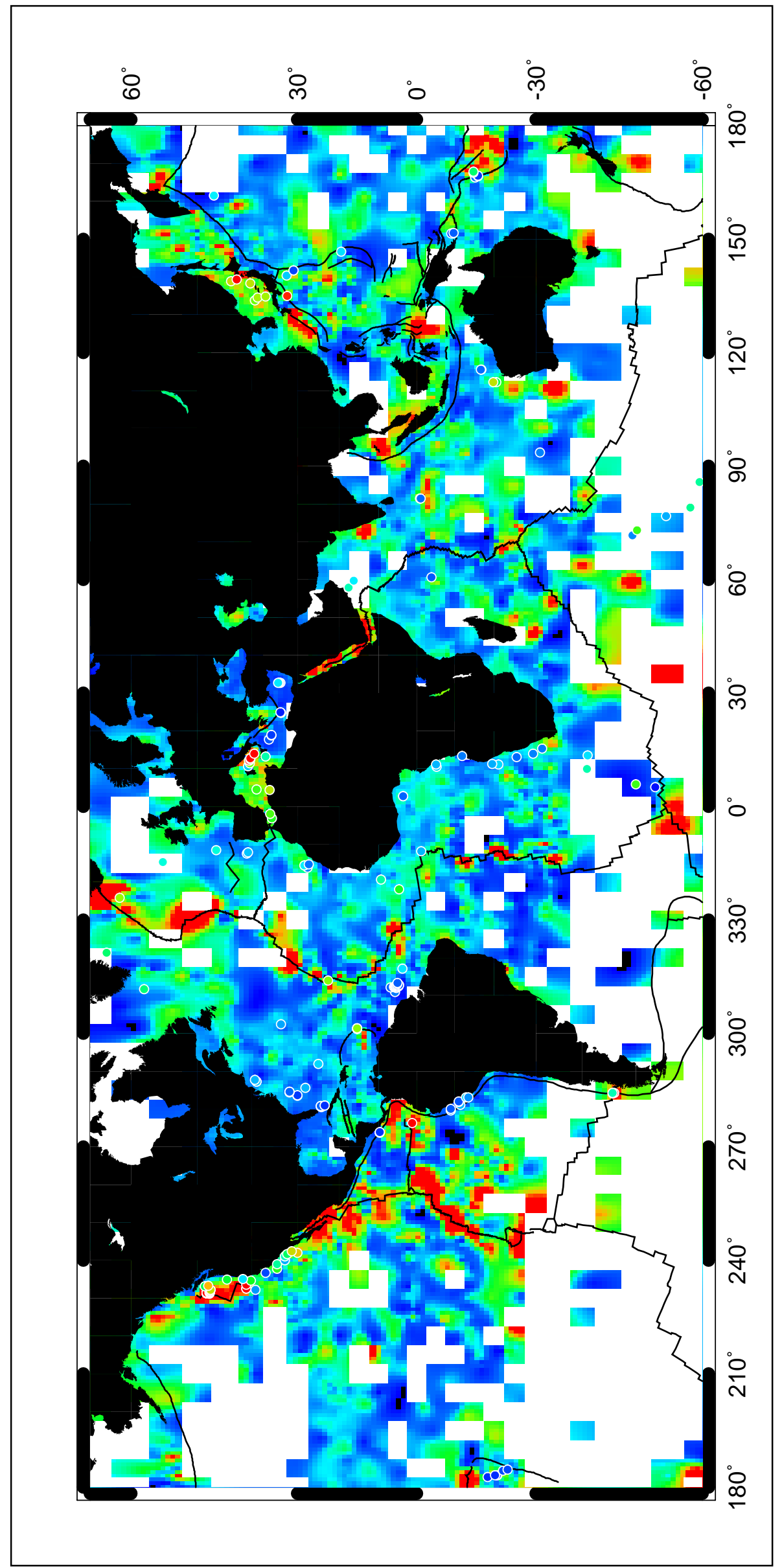




\section{Available Data}

The data used in this study and our results are made available in various formats: ASCII, PDF and MS EXCEL97 files on the included CD.

\subsection{Temperature Data}

The results of individual sea floor and sediment temperature measurements are listed as tab-delimited ASCII text in ODPTemp.txt. The three columns are (1) site, (2) depth in meters below sea floor (mbsf), and (3) extrapolated equilibrium temperature in ${ }^{\circ} \mathrm{C}$.

\subsection{Thermal Conductivity and Resistivity Data}

If available, thermal properties of sediments are listed for sites with sediment temperatures as tab-delimited ASCII text in ODPThC.txt. The six columns are (1) site, (2) depth in meters below sea floor (mbsf), (3) shipboard thermal conductivity in $\mathrm{W} \mathrm{m}^{-1} \mathrm{~K}^{-1}$, (4) in-situ corrected thermal conductivity in $\mathrm{W} \mathrm{m}^{-1} \mathrm{~K}^{-1}$ (eq. 13), and (5) cummulative thermal resistance in $\mathrm{m}^{2} \mathrm{~K} \mathrm{~W}^{-1}$ (Section 2.3.2).

\subsection{Heat Flow Calculations}

Heat flow calculations are provided as MS EXCEL97 files. Table 1 shows an example. The top of the left three columns contain depth $z$ (mbsf: meters below sea floor), the individual temperature values $\left(T(z)\right.$ in $\left.{ }^{\circ} \mathrm{C}\right)$, and thermal resistance $\left(\operatorname{tr}(z)\right.$ in $\left.\mathrm{m}^{2} \mathrm{~K} \mathrm{~W}^{-1}\right)$ calculated according to the thermal conductivity approach used (Section 2.3.2). In the fifth column, heat flow is calculated for each interval of temperature values as a function of depth $(q(z)$ in $\mathrm{mW} \mathrm{m}^{-2}$ ) from the slope of temperature versus thermal resistance (Section 2.3.5). The top of column six shows the average heat flow for this site $(q)$ calculated from a linear regression of all temperature versus thermal resistance values from columns two and three. Below, the correlation coefficient (correl $q$ ) is given. In the center of column six, the temperature gradient $(g T)$ is calculated from columns one and two together with a correlation coefficient (correl $g T)$. In addition, the sea floor temperature is extrapolated from the given sediment temperatures ( $T 0$ from intercept in ${ }^{\circ} \mathrm{C}$ ), and the slope of heat flow versus depth $(q(z)$, column five) is calculated. In the lower part of the spreadsheet, shipboard thermal conductivity values (column two) are corrected for in-situ conditions (eq. 13) and then fitted with an average, linear regression or porosity-related approach (Sections 3.2.2.1, 3.2.2.2, and 3.2.2.3, respectively). The fitting results are listed below therm con in column seven. These values are used to calculate the cummulative thermal resistance (therm res in column five and $\operatorname{tr}(z)$ at the top of column three). Further below to the right the parameters necessary to perform the in-situ corrections (insitu corr.) are listed (eq. 13): water depth (taken from IR volumes), sediment density (generally assumed to be $1.8 \mathrm{~g} \mathrm{~cm}^{-3}$ ), sea floor temperature (taken from top of column two), mean gradient (taken from $g T$ in column six) and laboratory temperatures during thermal conductivity measurements (generally assumed to be $15^{\circ} \mathrm{C}$ ). 
Table 1: Example of provided MS EXCEL 97 spreadsheet for individual heat flow calculations.

$\begin{array}{rrrcccr}\operatorname{mbsf} & \mathrm{T}(\mathrm{z}) & \operatorname{tr}(\mathrm{z}) & & & \mathrm{T} 0 \text { from intercept } & \text { slope of q(z) } \\ & & & & \mathbf{q ( z )} & \begin{array}{c}\mathbf{q} \\ (\mathbf{m W} / \mathbf{m} \mathbf{2})\end{array} & \\ 0.00 & 1.80 & 0.00 & & \mathbf{4 1 8} & -15.35 & 36608.7 \\ 57.20 & 20.40 & 49.55 & 375 & \text { correl q } & & \\ 67.60 & 26.90 & 58.15 & 756 & 0.99 & \end{array}$

gT (K/km)

356

correl gT

0.99

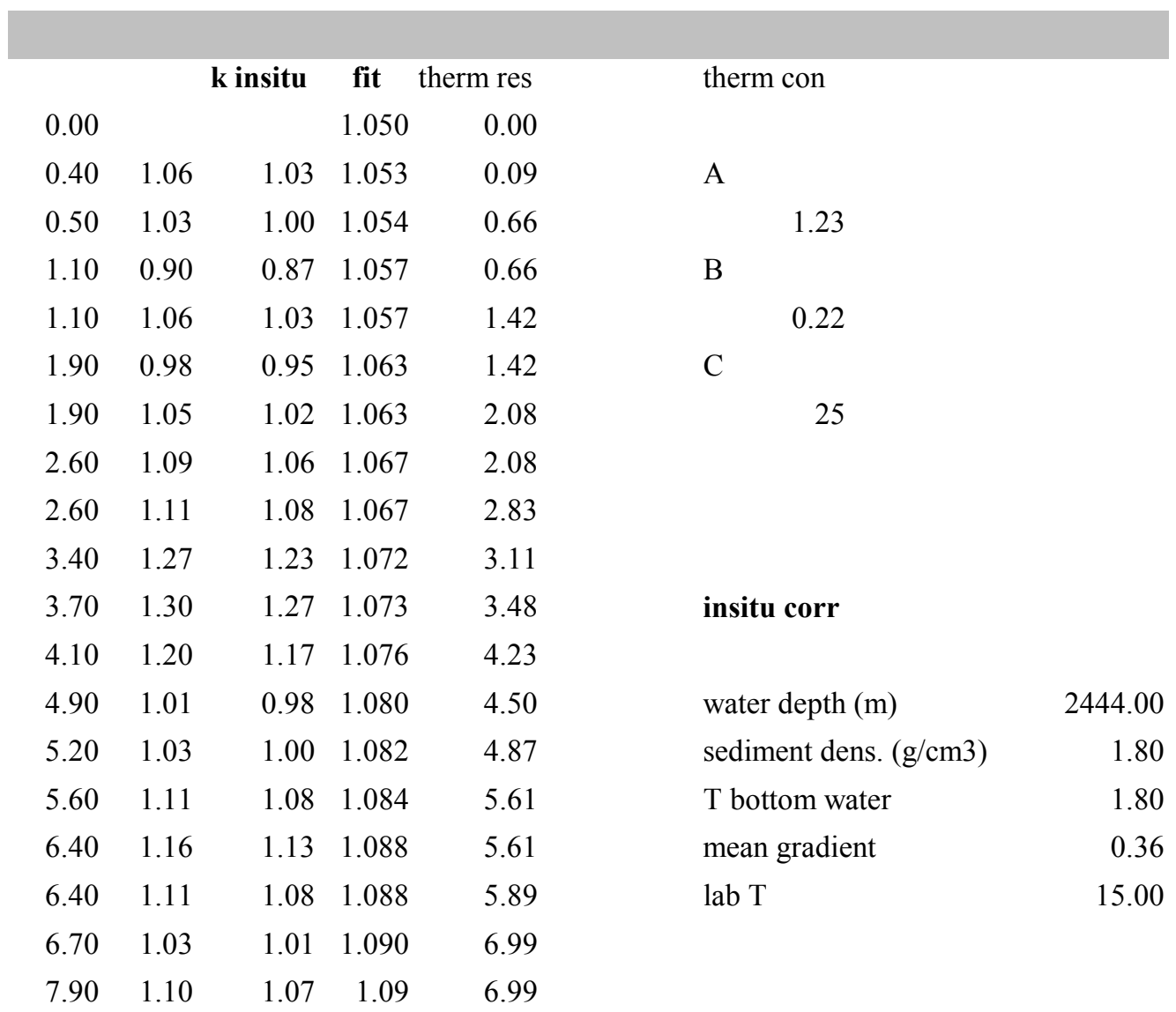




\subsection{Bullard Plots}

The spreadsheets discussed in Section 5.3 are used to create Bullard Plots for each site (Section 2.3.1 and Figure 10). All Bullard Plots are available in PDF format in Bullards.pdf. For each site, three graphs are shown (Figure 17): (1) extrapolated equilibrium temperatures versus depth with linear regression, (2) in-situ corrected shipboard thermal conductivity versus depth together with appropriate fit, and (3) temperature versus cummulative thermal resistance with linear regression. In most but not all cases, the depth axes of the first two graphs have identical limits. (Note that the vertical axis of the third graph is not depth.)
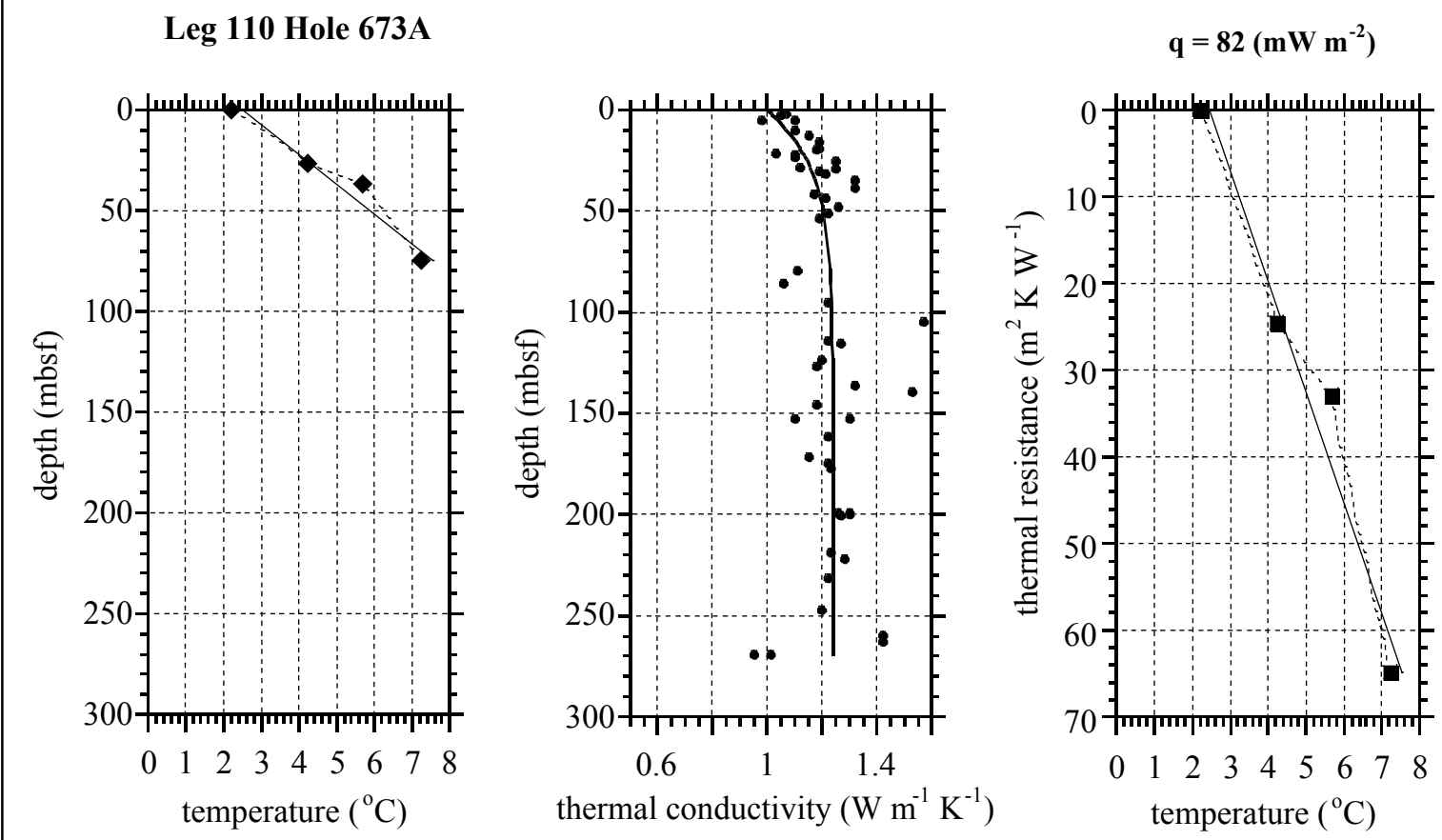

Figure 17: Example of a Bullard Plot; left: extrapolated equilibrium temperatures versus depth (diamonds, connected by dotted line) with linear regression (solid line); center: in-situ corrected shipboard thermal conductivity measurements (dots) with appropriate fit (line): right: temperature versus cummulative thermal resistance (squares, connected by dotted line) with linear regression (solid line). 


\subsection{Summary}

The results of this synthesis are summarized in three files.

\subsubsection{Summary of Temperature Data}

The summarized temperature data is available as tab-delimitted ASCII format in sum_tmp.txt and in PDF format in sum_tmp.pdf. The columns are: (1) leg number, (2) site number, (3) latitude and (4) longitude of the site (in degrees, $\mathrm{N}$ positive, $\mathrm{S}$ negative, E positive, W negative), (5) temperature tools used (see Section 2.2), (6) number of individual temperature measurements, (7) maximum depth of measurements (in mbsf), and (8) temperature gradient (in $\mathrm{K} \mathrm{km}^{-1}$ ).

\subsubsection{Summary of Thermal Conductivity Data}

The summarized thermal conductivity data is available as tab-delimitted ASCII format in sum_thc.txt and in PDF format in sum_thc.pdf. The columns are: (1) leg number, (2) site number, (3) latitude and (4) longitude of the site (in degrees, $\mathrm{N}$ positive, $\mathrm{S}$ negative, E positive, $\mathrm{W}$ negative). The next columns provide the results of one appropriate thermal conductivity fit: average approach (Section 2.3.2.1): column (5) lists the average thermal conductivity $k_{\text {av }}$ (eq. 3) in $\mathrm{W} \mathrm{m}^{-1} \mathrm{~K}^{-1}$; or linear approach (Section 2.3.2.2): column (6) lists the sea floor thermal conductivity $k(0)$ in $\mathrm{W} \mathrm{m}^{-1} \mathrm{~K}^{-1}$ and column (7) the slope in $\mathrm{W} \mathrm{m}^{-2} \mathrm{~K}^{-1}$ as a result of a linear regression (eq. 5); or the porosity-related approach (Section 2.3.2.3): column (8) lists the matrix thermal conductivity $k_{\text {mat }}$ in $\mathrm{W} \mathrm{m}^{-1} \mathrm{~K}^{-1}$, column (9) the sediment porosity at the sea floor phi(0), and column (10) the characteristic depth $D$ in mbsf from the fit to equations (7) and (8).

\subsubsection{Summary of Heat Flow Data}

The summarized heat flow data is available as tab-delimitted ASCII format in sum_hf.txt and in PDF format in sum_hf.pdf. The columns are: (1) leg number, (2) site number, (3) latitude and (4) longitude of the site (in degrees, N positive, S negative, E positive, $\mathrm{W}$ negative), (5) reported heat flow in $\mathrm{mW} \mathrm{m}^{-2}$ (if available), (6) recalculated heat flow in $\mathrm{mW} \mathrm{m} \mathrm{m}^{-2}$, (7) quality rating, and (8) comments, e.g. explanation for a rating lower than $\mathrm{A}$. The comments are $k(z)$ insuff: not enough thermal conductivity measurements available, $k(z)$ assumed: thermal conductivity was estimated due to lack of available measurements, $k$ insitu: the applied in-situ correction for shipboard thermal conductivity measurements (eq. 12) is questionable due to exceptionally high temperatures, only $1 T$ : only one sediment temperature measurement available, $T$ scanned from figure: temperature values were only available as figure in IR volumes and had to be scanned, $T$ new: equilibrium temperatures have been reextrapolated (Section 2.2), var. gradT: medium to large variations in the temperature gradient, flow?: variation in temperature gradient suggests possible influence of fluid flow.

Acknowledgements. We are most thankful to scientits and staff of ODP, Tamu, and LDEO for their help. This work was supported by NSF grant OCE-9634140 and DFG grant Pr 471/2. 


\section{References}

Barnes, R. O., Operation of the IPOD in situ pore water sampler, In Sibuet, J.-C., Ryan, W.R.F., et al., Proc. DSDP, Init. Repts., 47 (2), Washington, D. C., US Govt. Printing Office, 19-22, 1979.

Barnes, R. O., In-situ fluid sampling and measurement: a new wireline tool, In Mascle, A., Moore, J. C., et al., Proc. ODP, Init. Repts., 110 (A), College Station, TX (Ocean Drilling Program), 55-63, 1988.

Blum. P., A. Rabaute, P. Gaudon, and J. Allan, Analysis of natural gamma-ray spectra obtained from sediment cores with the shipboard scintillation detector of the Ocean Drilling Program: example from Leg 156, In Shipley, T.H., Ogawa, Y., Blum, P., and Bahr, J.M.: Proc. ODP, Sci. Repts., 156, College Station, TX (Ocean Drilling Program), 1997.

Bullard, E.C., Heat Flow in South Africa, Proc. R. Soc. London A, 173, 474-502, 1939.

Clark, H., Thermal Conductivity, Handbook of Physical Constants, Memoir 97, Geol. Soc. of America, 459-482, 1966.

Clauser, C., and E. Huenges, Thermal conductivity of rocks and minerals, in Rock Physics and Phase Relations: A Handbook of Physical Constants, Volume 3, Ahrens, T. J.(ed.), 105126, American Geopysical Union, Washington D.C., 1995.

Davis, E.E., M.J. Mottl, A.T. Fisher, et al., Proc. ODP, Init. Repts., 139, College Station, TX (Ocean Drilling Program), 55 - 97, 1992.

Davis, E.E., A.T. Fisher, J.V. Firth et al., Proc. ODP, Init. Repts., 168, College Station, TX (Ocean Drilling Program), 470, 1997a.

Davis, E.E., H. Villinger, R.D: MacDonald, R.D. Meldrum, and J. Grigel, A robust rapidresponse probe for measuring bottom-hole temperatures in deep-ocean boreholes, $\mathrm{Ma}$ rine Geophys. Res., 19, 267-281, $1997 \mathrm{~b}$.

Davis, E.E., D.S. Chapman, H. Villinger, S. Robinson, J. Grigel, A Rosenberger, and D.F.C. Pribnow, Seafloor heat flow on the eastern flank of the Juan de Fuca Ridge: data from "FlankFlux" studies through 1995, In: Davis, E.E., A.T. Fisher, J.V. Firth et al., Proc. ODP, Init. Repts., 168, College Station, TX (Ocean Drilling Program), 23-33, 1997c.

Horai, K. and R. P. Von Herzen, Measurement of heat flow on leg 86 of the Deep Sea Drilling Project, Proc. DSDP, Init. Repts.,, 86, 759-777, 1985.

Hyndman, R.D., A.J. Erickson, and R.P. von Herzen, Geothermal Measurements on DSDP Leg 26, In Davies, T.A., Luyendyk, B.P., et al.,: Proc. DSDP, Init. Repts., 26, 451-463, 1974.

Pribnow, D.F.C., E.E. Davis, and A.T. Fisher, Borehole heat flow along the eastern flank of the Juan de Fuca Ridge, including effects of anisotropy and temperature dependence of sediment thermal conductivity, J. Geophys. Res., 105, 13449-13456, 2000.

Ratcliffe, The thermal conductivities of ocean sediments, J. Geophys. Res., 65, 1535-1541, 1960.

Rybach, L., Radioactive heat production, a physical property determined by the chemistry of rocks, in R.G.J. Strens (ed): The Physics and Chemistry of Minerals and Rocks, 309318, Wiley and Sons, London, 1976.

Yokota, T., Kinoshita, H., and S. Uyeda, New DSDP (Deep Sea Drilling Project) downhole temperature probe utilizing ICRAM (memory) elements, Bull. Earthquake Res. Inst., Tokyo Daigakai Jishin Kenky Usho Iho, 55, part 1, 75-88, 1980. 
Von Herzen, R.P., and A.E. Maxwell, the measurement of thermal conductivity of deep-sea sediments by a needle probe method, J. Geophys. Res., 64, 1557-1563, 1959. 